\title{
FACTORS AFFECTING AGROBACTERIUM MEDIATED TRANSFORMATION OF INDIGENOUS CHLORELLA VULGARIS BAYERINCK
}

\author{
Nadia Sharif, Neelma MuniR*, Faiza Saleem and Shagufta Naz \\ Department of Biotechnology, Lahore College for Women University, Lahore, Pakistan
}

Key words: Acetosyringone, Transformation, Chlorella vulgaris

\begin{abstract}
Chlorella vulgarisis Bayerinck widely used as a health food, feed supplement, as well as in the pharmaceutical, biofuel and cosmetics industries. It has been used to determine optimum transformation conditions through Agrobacterium tumefaciens. It has been revealed that bacterial density of $\mathrm{OD}_{600}=1.0,3$ days of co-cultivation at $25^{\circ} \mathrm{C}$ in $\mathrm{pH} 5.5$, and $100 \mu \mathrm{M}$ acetosyringone are the optimum conditions to transform C. vulgaris.
\end{abstract}

Microalgae are sources of dropping fuels, feed, fertilizer, nutritional oils and pharmaceutical products (Borowitzka 2013). It contains proteins, carotenoids, lipids, immune stimulator compounds, polysaccharides, vitamins, antioxidants and minerals products (Chisti 2007, Wang and Zhang 2013). They are used in waste water treatment and other remediation services (Lizzul et al. 2014). Potentiality of growth of the alga is the key feature for efficient application at low production cost. Genetic engineering of algae is used to improve the algal strain in biomass productivity as well as potential fuel strength to make it more sustainable and economical. During last several years researchers have improved oil yield and biomass production by gene splicing and modification in lipids synthesis pathways. Stable nuclear transformants of algae have been achieved by electroporation, agitation with glass beads or silicon carbide whisker, particle bombardement and Agrobacterium tumefaciens mediated transformation. Major limitations of the transformation methods were overcome by Agrobacterium-mediated transformation (Tara et al. 2005, Shrawat and Lorz 2006).

To produce high quality biomass, attention must be paid to culture conditions where nutrients in the medium play a major role in the cultivation of algae (Jayaramareddy et al. 2014). Largescale production of Chlorella biomass depends on nutrient availability, temperature and light which influence the composition of the biomass by changes in metabolism. The cellular lipid content and polyunsaturated fatty acids decrease with increase in light intensity (Li et al. 2011, Widjaja et al. 2009). Natural day light and $25-30^{\circ} \mathrm{C}$ temperature are favorable for overall growth of Chlorella vulgaris Bayerinck. Higher $\mathrm{pH}$ lowers the affinity of Chlorella to free $\mathrm{CO}_{2}$ and under conditions of alkaline $\mathrm{pH}$ less unsaturated membrane lipids is produced (Rekha et al. 2012).

Although the application of genetic engineering to improve Chlorella strains for polysaccrides and fatty acids is in its infancy, significant advances have been achieved in the development of genetic manipulation tools to manipulate central carbon metabolism in microorganisms (Radakovits et al. 2010). Advantages of Agrobacterium-mediated transformation method over direct gene transfer methods include its feasibility to transfer large DNA fragments, low copy number of transgene integration with little rearrangement, preferential integration into transcriptionally active regions and its simplicity (Cha et al. 2012).

*Author for correspondence: <neelma.munir@yahoo.com>. 
Chlorella vulgaris was collected from Jallo Park (Lahore, Pakistan) and observed under light microscope for their morphological features and other cellular details (Graham et al. 2009). Optimization of $\mathrm{pH}$ and temperature were determined and uniculture was obtained periodically by repeating culturing in liquid and agar media.
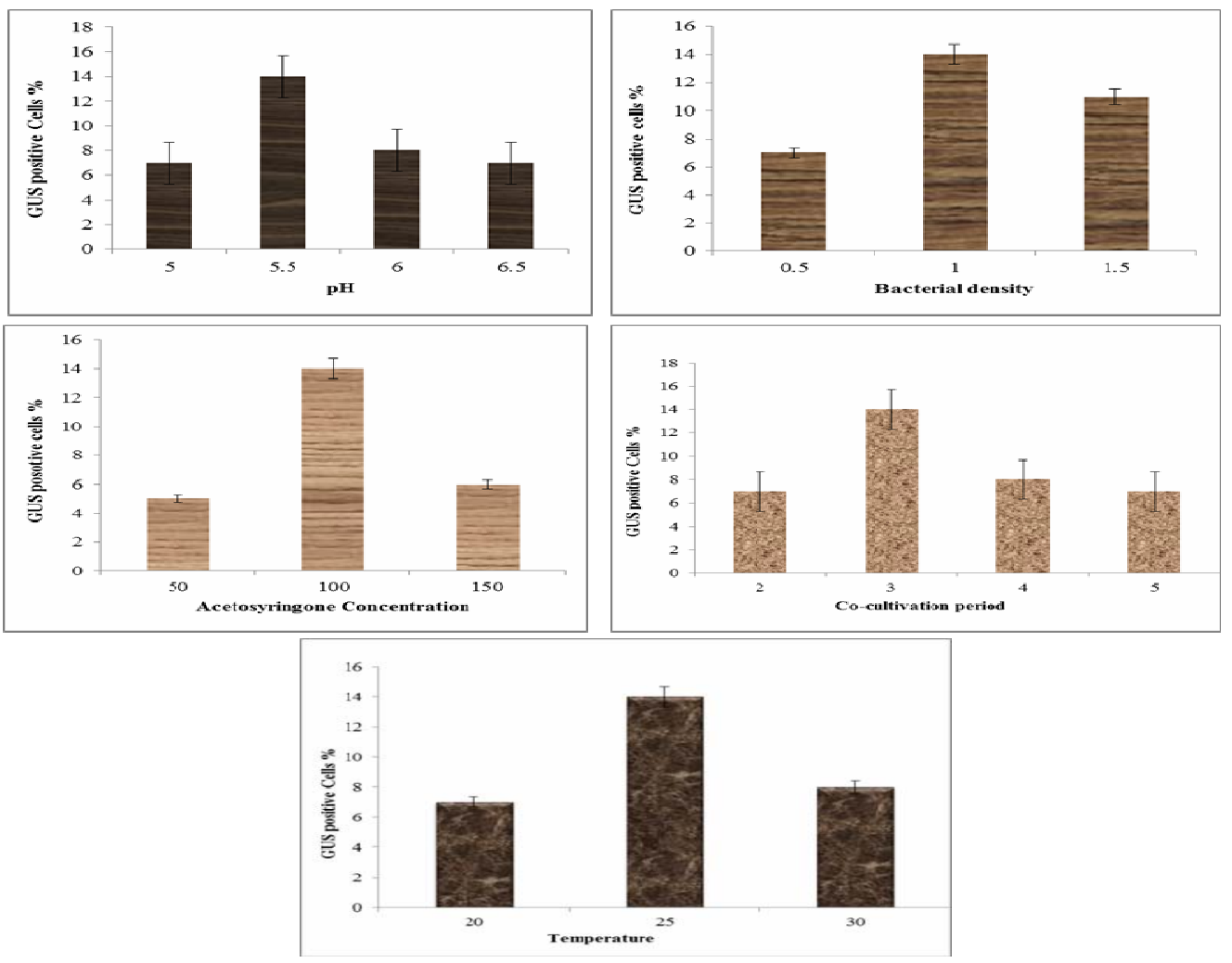

Fig. 1. Influence of different parameters on Agrobacterium-mediated transformation of Chlorella vulgaris.

To optimize the growth parameters, each parameter (inoculum density, co-cultivation duration, $\mathrm{pH}$ of co-cultivation medium, concentration of acetosyringone) was optimized by keeping other parameters constant. For Agrobacterium mediated transformation first $C$. vulgaris was cultivated on BB agar media (Bold 1949). For transformation A. tumefaciens stock of EHA 101 (pZY 102) was made by streaking on solidified LB medium containing appropriate antibiotics and incubated for 3 days at $28^{\circ} \mathrm{C}$. The day before explant inoculation, liquid LB medium containing antibiotics was inoculated with a single colony and kept on shaker until $\mathrm{OD}_{650}$ reached 1.2. Then the culture was centrifuged to pellet the cells. The pellet was subsequently re-suspended in liquid co-cultivation medium and shaken at $220 \mathrm{rpm}$ for $30 \mathrm{~min}$ before inoculation. The bacterial suspension was spread on the thin layer of $C$. vulgaris culture $\left(5 \times 10^{6}\right)$ growing on agar plate supplemented with acetosyringone. The plate was incubated for 2 days in the dark at $25^{\circ} \mathrm{C}$ (Co-cultivation).

The co-cultivation algal cells were recovered by growing in BBM supplemented with cefotaxime and incubated to eliminate $A$. tumefaciens. The harvested cells were washed twice with liquid BB medium via resuspension by mild vortexing and centrifugation. Histochemical GUS 
assay was performed for transformed and untransformed cells (Liu et al. 2013). In order to study the effects of each parameter on the transformation frequency, one parameter was first varied while other parameters were kept constant based on the findings of the preliminary experiments and general transformation procedure above.

All of the parameters were optimized by screening for transient GUS expression. No expression of reporter genes was detected in non-transformed cells. The effects of the assayed parameters which were known to influence the efficiency of Agrobacterium-mediated transformation are given in Fig. 1.

Results indicate that microalgae cells pre-culture duration significantly affects the percentage of GUS expressing cells. Several reports noted that the overgrowth and high density of Agrobacterium cause explants mortality (Ghimire et al. 2008, Ozawa 2009). A high density of bacteria $(\mathrm{OD} 600=1.0)$ did not affect transformation frequency. The concentration of acetosyringone apparently influences the transformation frequency (Cha et al. 2012).

\section{Acknowledgement}

The authors want to thank "Higher Education Commission (HEC), Pakistan for the financial support awarded to MS. Nadia Sharif for her PhD studies (1500006861/3244).

\section{References}

Bold HC 1949. The morphology of Chlamydomonas chlamydogama sp. Bull. Torr. Bot. Club. 76: 101-108.

Borowitzka MA 2013. High-value products from micro algae - their development and commercialisation. J. App. Phycol. 25(3): 743-756.

Cha TS, Yee W and Aziz A 2012. Assessment of factors affecting Agrobacterium-mediated genetic transformation of the unicellular green alga, Chlorella vulgaris. World. J. Microbiol. Biotechnol. 28: 1771-9.

Chisti Y 2007. Biodiesel from microalgae. Biotechnol. Adv. 25: 294-306.

Ghimire BK, Seong ES, Lim JD, Heo K, Kim MJ, Chung IM, Juvik JA. and Yu CY 2008. Agrobacteriummediated transformation of Codonopsis lanceolata using the c-TMT gene. Plant Cell Tiss. Organ Cult. 95: 265-274.

Graham LE, Graham JM and Wilcox LW 2009. Algae. Pearson Education, San Francisco, CA.

Jayaramareddy D, Krishnappa R and Thimmappa GS 2014. Microalgae Cultivation in Different pH, Temperature and Media for Lipid Production. Int. J. Life Sci. 8: 13-17.

Lizzul A, Hellier P, Purton S, Baganz F, Ladommatos N. and Campos L 2014 Combined remediation and lipid production using Chlorella sorokiniana grown on wastewater and exhaust gases. Bioresour. Technol. 151: 12-18.

Li Z, Yuan H, Yang J and Li B 2011 Optimization of the biomass production of oil algae Chlorella minutissimaUTEX2341. Bioresour. Technol. 102: 9128-9134.

Liu L, Wang Y, Zhang Y, Chen X, Zhang P and Ma S 2013 Development of a new method for genetic transformation of the green alga Chlorella ellipsoidea. Mol. Biotechnol. 54: 211-21

Ozawa K 2009. Establishment of a high efficiency Agrobacterium-mediated transformation system of rice (Oryza sativa L.). Plant. Sci. 176: 522-527.

Radakovits R, Jinkerson RE, Darzins A and Posewitz MC 2010. Genetic engineering of algae for enhanced biofuel production. Eukary. Cell. 9: 486-501.

Rekha S, Gajendra PS and Vijendra KS 2012. Effects of culture conditions on growth and biochemical profile of Chlorella vulgaris. J. Plant Path. Microbiol. 3: 1-6.

Shrawat AK and Lorz H 2006. Agrobacterium mediated transformation of cereals: a promising approach crossing barriors. Plant. Biotech. J. 4: 575-603. 
Tara LW, Chris C and Saul P 2005. Algal transgenics in the Genomic era. J. Phycol. 41: 1077-093.

Wang X. and Zhang X. 2013. Separation, antitumor activities, and encapsulation of polypeptide from Chlorella pyrenoidosa. Biotechnol. Prog. 29: 681-7.

WidjajaA, Chien CC and Ju YH 2009. Study of increasing lipid production from fresh water microalgae Chlorella vulgaris. J. Taiwan Inst. Chem. Eng. 40: 13-20.

(Manuscript received on 25 September, 2014; revised on 15 April, 2015) 